\title{
Effects of thermal ageing on the microstructure of an API 5L X52 pipeline steel
}

\author{
${ }^{*}$ C. Angeles-Chavez, ${ }^{* * *}$ P. Morales, ${ }^{* *}$ M. Palomar
}

*Instituto Mexicano del Petróleo, Programa de Investigación y Desarrollo de Ductos, Eje Central Lázaro Cárdenas 152, CP 07730. México D.F. México

**Universidad Autónoma Metropolitana-Azcapotzalco, Depto. de Materiales, Av. San Pablo 180. CP. 02200, México D.F. México.

Pipeline steel API 5L X52 has been used frequently for the hydrocarbon transport in the petroleum industry due to their excellent corrosion resistance by the formation of a stable passive film [1]. However, their mechanical properties are affected for the long service time used producing change in the microstructure, growth of precipitates at the grain boundary as well as in the matrix affecting the corrosion behavior of these pipeline steel significantly [2].

Few studies has been focused to determinate the magnitude of the microstructural changes in the X52 pipeline steel that currently are in use. To obtain an estimate of the phenomena an aging process accelerated using treatment heat at different temperature has been carried out. These studies have been carried out mainly on the stainless steel $[3,4]$

In this work we presented preliminary results of microstuctural changes of a X52 pipeline steel aged at two temperature $\left(50\right.$ y $\left.250{ }^{\circ} \mathrm{C}\right)$ and different aging time $(100,500$ and $1000 \mathrm{~h})$. The samples were analyzed by scanning electron microscopy (SEM) and energy dispersive spectroscopy (EDS). Several micrographs were taken to measure the grain size number and the grain size. The norm ASTM E112 was used for this case

Figure 1 show the microstructure of the sample as-received. Two typical phases can be observed in micrograph: Ferrite (contrast gray) and perlite (white contrast) phases. In general, no great changes in the microstructure of the other samples were observed at single view; however when the grain size was measured can be easily detected a change in the grain size number. The table 1 shows the grain size number and grain size of the samples in the different test conditions. The results of table shows that when the aging time is increased the grain size number is decreased therefore the grain size is increased $\left(50\right.$ and $\left.250{ }^{\circ} \mathrm{C}\right)$. Also can be observed that the increase of the temperature produce a decreased in the grain size number and therefore an increase in the grain size. Particles in the grains were observed and a typical particle is illustrated in the micrograph of figure 2a. Chemical analysis carried out in the particles shows that are inclusions (exogenous type) due to their chemical components, mainly $\mathrm{Al}, \mathrm{O}$ and $\mathrm{Ca}$, which is illustrated in the spectrum of figure $2 \mathrm{~b}$. Precipitates not were found by SEM; a transmission electron microscopy study is required for this case.

\section{References}

1. J.F.D. Stott, Corrosion Science, 35, 1993, 667.

2. S. Al-Hassan, B. Mishra, D.L. Olson and M.M. Salama, Corrosion, 54, 1998, 480.

3. P. Han-Hin, K. and Hyuk-Sang, Corrosion Science, 44, 2002, 2817.

4. P. Muraleedharan, J.B. Gnanamoorthy and P. Rodriguez, Corrosion Science, 38, 1996, 1187. 


\begin{tabular}{|l|l|l|l|l|}
\hline \multicolumn{2}{|c|}{ Table 1. Results of grain size number and their corresponding grain size } \\
\hline $\begin{array}{c}\text { Aging Time } \\
(\mathrm{h})\end{array}$ & $\begin{array}{c}\text { Grain Size } \\
\text { Number }\end{array}$ & $\begin{array}{c}\text { Grain Size } \\
(\mu \mathrm{m})\end{array}$ & $\begin{array}{c}\text { Grain Size } \\
\text { Number }\end{array}$ & $\begin{array}{c}\text { Grain Size } \\
(\mu \mathrm{m})\end{array}$ \\
\hline As- received & 9.63 & 11.35 & 9.63 & 1135 \\
\hline & \multicolumn{2}{|c|}{$50{ }^{\circ} \mathrm{C}$} & \multicolumn{2}{c|}{$100{ }^{\circ} \mathrm{C}$} \\
\hline 100 & 9.63 & 11.80 & 9.08 & 13.75 \\
\hline 500 & 8.89 & 14.72 & 8.75 & 15.43 \\
\hline 1000 & 8.75 & 15.50 & 8.69 & 15.91 \\
\hline
\end{tabular}

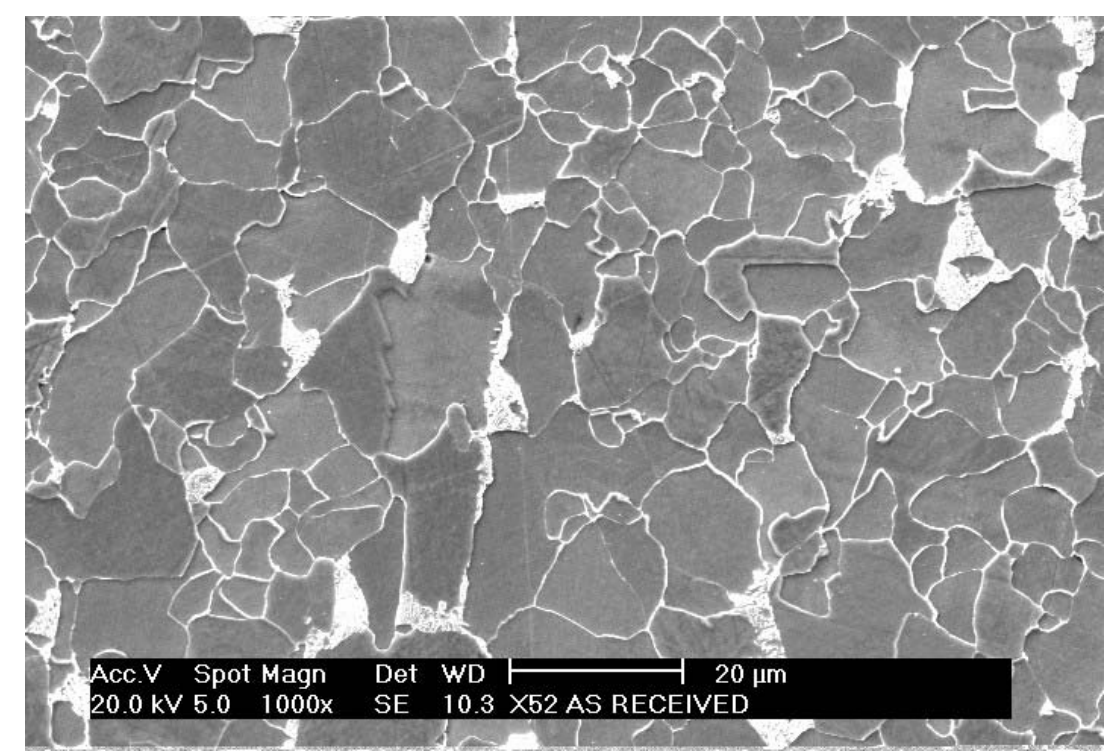

Figure 1. Typical microstructure observed in the sample As-Received.

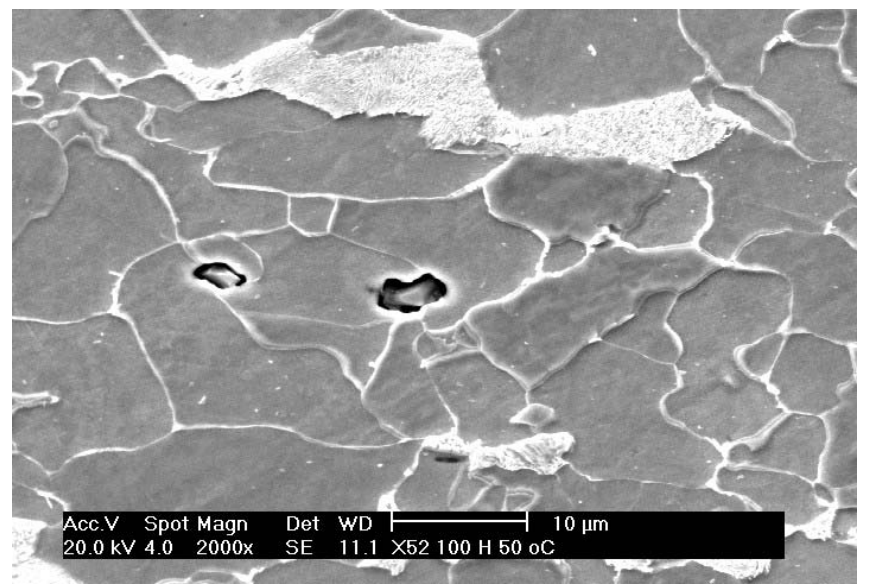

(a)

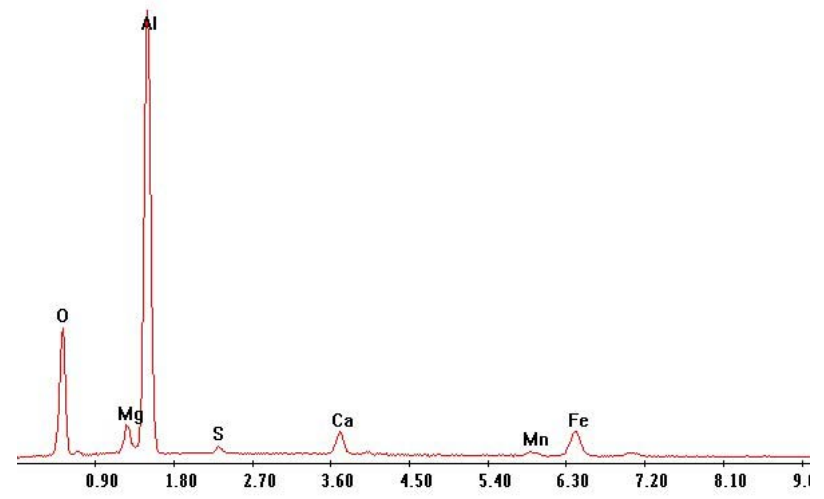

(b)

Figure 2. SEM micrograph illustrating a)particles in the grain and b)typical chemical elements detected in the particles 